\title{
The Impact of Self on Materialism among Teenagers
}

\section{ABSTRACT}

No previous research has investigated the relationship between the concept of self and $=$ materialism, especially among teenagers. Our study seeks to reverse this trend by examining how independent self-construal and interdependent self-construal affects materialism among Brazilian teenagers (grades 7 through 12). Hypotheses were tested using structural equation modelling. We find that independent self-construal has a positive effect on materialism. Furthermore, we created three sub-constructs out of the original interdependent self-construal construct, none of which affected materialism in the same way. Group dependency, a need to achieve the group's authorisation, increases materialism; group loyalty, an attitude of group fidelity, has no effect on materialism; and group respect, a respect for group decision, diminishes materialism. These are interesting results, since they question our prior beliefs on the matter, and introduce new factors into the scholarly discussion of this issue.

Key words: self-concept, materialism, teenagers, Brazil, independent self-construal, interdependent self-construal.

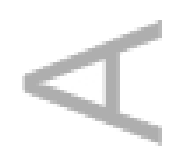

This is the author manuscript accepted for publication and has undergone full peer review but has not been through the copyediting, typesetting, pagination and proofreading process, which may lead to differences between this version and the Version of Record. Please cite this article as doi: $10.1002 /$ cb.1573 


\section{The Impact of Self on Materialism among Teenagers}

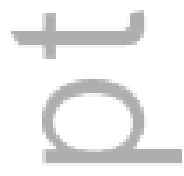

$=$

\section{INTRIDUCTION}

Previous research has investigated materialism in the context of adolescents. Chaplin and John (2007) showed that materialism is closely related to self-esteem in children between the ages of 8 and 18. It is in this transitional period that the individuals choose their level of independency and interdependency from others (Gulland, 2006). Belk (1988) shows that teenagers seek self-identity by acquiring and accumulating a selection of consumption objects, and other studies conclude that indeed teen consumption focuses on specific things that friends use, the so called 'right things' as a way to fit into their social group (Kantrowitz \& Wingert, 1999; Lindstrom, 2003; Moses, 2000; Muniz \& O'Guinn, 2001; Siegel, Coffey, \& Livingston, 2001). In addition, Solomon (1983) suggests that teens tend to create shared meanings with their peers, making their interpretation of reality fairly consistent with that of their social group. They even align their values to those of their friends, discussing ideas and expecting their support and understanding in response (Youniss \& Smollar, 1985).

Despite the previous research on materialism in teenagers, no research has examined the effect of self on materialism in teenagers. In this paper, we examine how the definition of the self has an effect on materialism among adolescents. Our research has three major contributions. 
First, this study examines the relationship between self-construal, both independent and interdependent, and materialism. Second, we test the conceptual model using data from a sample of teenagers. The focus on teenagers is particularly useful, we believe, not only because of the shortage of research about them, but also since adolescence is a transition filled with resolutions which will be carried beyond adolescence deep into adulthood, as an integral part of the self. Knowing what makes a teenager more or less materialistic could help us understand how they behave and make choices, and even may shed some light on their decisions as adults. Finally, this research focuses on Brazil, an emerging economy. The unique context of countries with emerging economy provides an interesting research context since recent studies show that these countries have increased purchasing power, and are likely to expand further (Morningstar, 2014). Thus, understanding consumer behaviours in these countries is important to marketers, wishing to expand their operations in these markets.

In the next section we provide a brief review of the literature on materialism and self. We then proceed to detail our research instrument and model, followed by our procedure and results. We conclude with implications from our results, the limitations of our study and suggestions for further research.

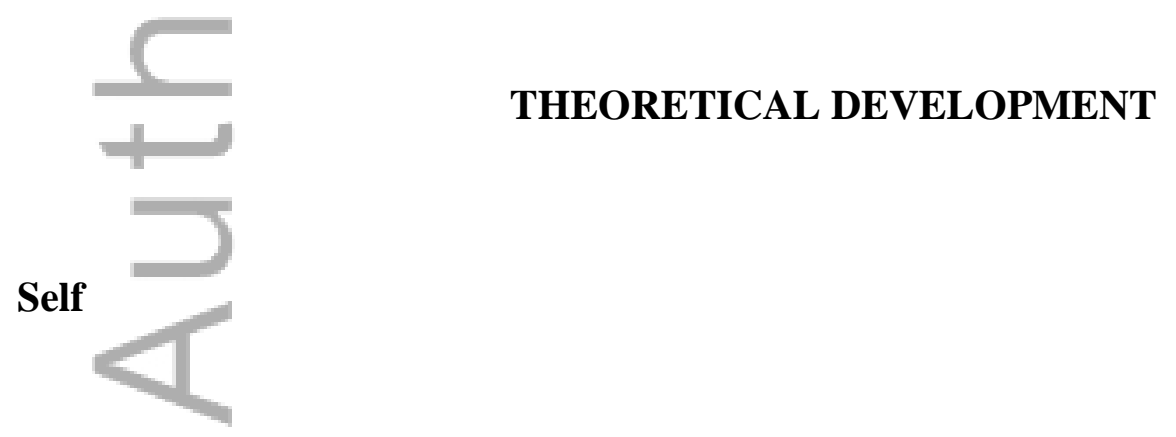


Most prior studies about self are found in the arenas of psychology and sociology (Brewer \& Hewstone, 2004), and studies connecting self with adolescent consumer behaviour are not large in number (Chaplin \& John, 2007). The self-concept encapsulates personal traits and characteristics like personality and self-perceptions. It is what comes to mind when we think about ourselves (Neisser, 1993).

Campbell et al. (1996) suggest that early researchers treated the self-concept as a unitary entity, a stable, comprehensive view of the self. Contemporary researchers rely on a multidimensional, dynamic construal of the self-concept. There are several constructs related to the self-concept. For instance there are ideal self, actual self, ought self (Higgins, Bond, Klein, \& Strauman, 1986; Sirgy, 1982), possible self (Markus \& Wurf, 1987), self-congruity (Grzeskowiak \& Sirgy, 2007; Sirgy, Lee, Johar, \& Tidwell, 2008), academic self-concept, social self-concept, and physical self-concept (Shavelson, Hubner, \& Stanton, 1976). The other dimensions of self that relate most directly to our study are self-concept clarity, independent self-construal, and interdependent self-construal. For our research, we use two dimensions of self (independent and interdependent) in an attempt to better capture such a complex aspect of an individual's life. According to parents, concepts such as independency and interdependency are very important during the teenager phase (Bristol \& Mangleburg, 2005)

In summary, the self is the way a person views herself (Krech, Crutchfield, \& Ballachey, 1962, p. 495-496). The self regulates intentional behaviour and permits the person to function efficiently in her social world (Banaji \& Prentice, 1994; Markus \& Wurf, 1987). An individual's 
evaluation of herself greatly influences her behaviour, and therefore, the more valued the self, the more organised and constant her behaviour becomes (Grubb \& Grathwohl, 1967).

\section{Materialism}

Materialism has been defined as "the importance a consumer attaches to worldly $=$

possessions" (Belk, 1984, p. 291) and as "the importance a person places on possessions and their acquisition as a necessary or desirable form of conduct to reach desired end states, including happiness”(Richins \& Dawson, 1992, p. 307). As proposed earlier by James (1890), a person's definition of herself is comprised of everything that she can call hers. According to Richins and Dawson (1992), true materialism is the pursuit of happiness through the acquisition of material things, yet we are interested in what could be called materialistic behaviour as well, in which materialism could also be a means to an end. The end is to express one's self through what one consumes (Belk, 1985; Czikszentmihalyi \& Rochberg-Halton, 1981; Holman, 1981; Mukerji, 1983; Solomon, 1983). Materialism affects what consumers expect from their possessions and which products they believe can fulfil their desires (Richins, 1994a).

Materialism is “a value that guides people's choices and conduct in a variety of situations, including, but not limited to, consumption arenas" (Richins \& Dawson, 1992, p. 307). The literature on materialism offers a background that helps researchers understand how consumers become attached to their belongings (Belk, 1985; Vigneron, 1998) and what are the implications for consumption meanings, self-identity (Zinkhan, 1994), charitable behaviour (Mathur, 2013) and teenagers (Schaefer, Hermans, \& Parker, 2004). 
Materialism is an orientation which views material goods as important for personal happiness and social progress (Ward \& Wackman, 1971). Although authors define materialism differently, their definitions share the following concept: that consumption is related to more than the instrumental or functional value of objects, suggesting that individuals seek a relationship with objects whereby they can improve themselves in some way. For this study we follow Richins (1987, p. 352) proposition that materialism is defined in terms of its role in consumer culture as "the idea that goods are a means to happiness; that satisfaction in life is not achieved by religious contemplation or social interaction, or simple life, but by possession and interaction with goods."

Some studies found high levels of materialism among adolescents (Fields, 1999; John, 1999). This is not surprising since a frequent theme of the modern consumer culture is that happiness can be purchased at the mall, on the Internet, in a catalogue, or on the iPhone (Kasser, 2002). In a recent study, Pieters (2013) finds that some kinds of materialism contribute to loneliness, yet other types of materialism help people get out of situations of solitude. It is possible adolescents could act more materialistic in order to avoid, or augment, their perceived levels of loneliness, of particular importance for people at those early stages, and this could depend on their perception of what is predominant on their self.

\section{Theoretical-Development: Self and Materialism}

Earlier research has shown that the 'self' could help predict some human behaviours related to materialism such as consumption motivation, purchase intention, tourism choices 
cognition, brands, seeking for uniqueness and advertising attitude (Grubb \& Grathwohl, 1967;

Markus \& Kitayama, 1991; Sirgy et al., 2008; Song \& Lee, 2013; Todd, 2001; Tsai, 2006), given that consumers attempt to gain acceptance into social groups through the products they purchase (Vigneron \& Johnson, 2004). Sirgy (1982) shows that consumer attitudes are consistent with their self-image and research reaffirms this concept, showing people create and communicate their self-image through the products they choose to consume (Belk, 1988; Kleine, Kleine, \& Allen, 1995; Richins, 1994b; Sirgy, 1982; Solomon, 1983; Wallendorf \& Arnould, 1988).

Everyone possesses dimensions of both independent and interdependent self-construal (Agrawal \& Maheswaran, 2005; Singelis, 1994). Yet, individuals are inclined to use one dimension of self-construal more than the other to guide their behaviour (Agrawal \& Maheswaran, 2005; Markus \& Kitayama, 1991). Independent self-construal "requires construing oneself as an individual whose behaviour is organised and made meaningful primarily by reference to one's own internal repertoire of thoughts" (Markus \& Kitayama, 1991, p. 226). One can conclude that an individual's behaviour is based on her independent self-construal, if her own internal attributes (e.g., feelings and thoughts) determine or cause her behaviour (Markus \& Kitayama, 1998).

Markus and Kitayama (1991, p. 226) suggest that interdependent self-construal "entails seeing oneself as part of an encompassing social relationship and recognising that one's behaviour is determined, contingent on, and to a large extent, organised by what one perceives to be the thoughts, feelings, and actions of others in the relationship". The important tasks for interdependent individuals are to fit into their group(s), act in suitable ways, promote their in- 
group goals and conform to their group(s). Consequently, the behaviour of individuals with a strong interdependent self is a reaction to others with whom they are interrelated (Markus \& Kitayama, 1998). Furthermore, individuals with a firm need to belong are likely to be prone to materialistic tendencies (Rose \& DeJesus, 2007).

Highly independent people are less susceptible to external influences (Wong \& Ahuvia, 1998) and focus more on internal experiences (Abe \& Bagozzi, 1996). The aforementioned empirical studies suggest that independent individuals are more likely to reject motivations that are socially generated. Furthermore, Clark's (2006) study of U.S. university students finds that global independency is negatively related to materialism. To summarise, an individual with a more independent 'self' values being able to take care of herself, while an individual with a more interdependent self gives higher importance to her family or group(s).

Conyentionally, it is suggested that teens' levels of materialism are high (Bristol \& Mangleburg, 2005; John, 1999; Larsen, Sirgy, \& Wright, 1999), but there is little explanation as to why this is. Research points in different directions; materialistic parents (Goldberg, Gorn, Peracchio, \& Bamossy, 2003), broken families (Rindfleisch, Burroughs, \& Denton, 1997; Roberts, Tanner, \& Manolis, 2005), level of wealth (Goldberg et al., 2003) and susceptibility to peer pressure (Achenreiner, 1997; Goldberg et al., 2003). It seems as if the elections made by teenagers on consumption patterns, and the importance they give to the possession of certain objects, could be closely related to how they define themselves against others, and by extension, on the prevalence of materialistic behaviour in them. 
Churchill and Moschis (1979) find that preferences of consumption differ between more independent and more interdependent consumers and suggest this is provoked by a stronger need for differentiation in consumers with a more pronounced independent self-construal.

Furthermore, Zollo (1999) shows that adolescents' material possessions have important consequences on their perception of their own self, and as mentioned above, Chaplin and John (2007) find that materialism is closely related to self-esteem in children between 8 and 18 years of age, so that materialistic behaviour could be reduced by boosting self-esteem. Based on this, we hypothesise that materialistic attitude could depend on what is dominant in them, independent self or interdependent self. This relationship between self-perception and materialism has not yet been studied.

This analysis leads us to the proposal of the following two main hypotheses:

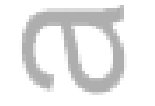

H1: Independent self-construal relates negatively to materialism.

H2: Interdependent self-construal relates positively to materialism.

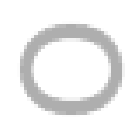

We propose a framework intending to investigate the following constructs: interdependent self-construal, independent self-construal and materialism, by using a scheme that represents a combination of interrelated fields such as consumer psychology, sociology and marketing, to examine how materialism is influenced by the dimensions of the 'self' (interdependent selfconstrual and independent self-construal). Figure 1 depicts the conceptual model. 
[Figure 1 Here]

\section{RESEARCH METHODOLOGY}

To test these hypotheses, a self-report survey was used to collect data from high school $=$

students in the state of São Paulo, Brazil. The population for this research consists of high school students between 12 and 19 years of age (grades 7 through 12). Three private high schools in the city of Santos were selected. Although in the US private schools are associated with affluence, this is not the case in Brazil, a country with a shortage of public high schools. Private schools are available and affordable for students in all socioeconomic sectors. With the intention of obtaining a diverse sample, tuition price was used as an indicator of socioeconomic status. The three selected schools represented an ample range of tuition.

Adolescence is a critical connection between childhood and adulthood, characterised by important physical, psychological, and social transitions. These transitions bring new risks but also present opportunities to positively impact the immediate and future of young people (Gilles, 2014). The teenage years are a development phase, which can determine values one might carry as an adult, influencing deeply how one self is formed. Teenagers have always been an important consumer group because they tend to be early adopters and because, traditionally, their brand preferences and consumer habits are not yet firmly defined (Lapowsky, 2014). Furthermore, teens are getting more materialist than older generations, which reiterate the importance to focus on this age group (Chee, 2013). 
Together with each school, students were recruited from approved classrooms. Before starting to answer all the students in the class with parental/guardian authorization were invited to complete the questionnaire. After that they were informed that their participation was voluntary (even with their parental authorizations) and that they could stop at any time. Nevertheless, they were not authorized by the school to leave the class in order to avoid noise and bother other classes. Furthermore, they were informed that any and all responses they provided would be held in the strictest confidence. It was also mentioned to the students that not even the school or parents would have access to individual data, all collected data and all classes in a specific school would be mixed and impossible to be separated. The total sample size obtained was 543 paper and pencil questionnaires. Two thirds of our sample are 16 or 17 years of age and most of them have only one sibling or none (73\%). Only $16 \%$ of them have some kind of work and $66 \%$ of their allowance pays for entertainment or clothes.

Measures

Developed in English, the instrument was translated into Portuguese by a native speaker and then translated back into English by a different native Portuguese speaker, who was not affiliated with this project. The instrument was pre-tested with 50 students and reliability was satisfactorily assessed for the constructs, with an acceptable range of Cronbach's alpha coefficients near .70 or better (Kline, 2000; Nunnally \& Bernstein, 1994).

The independent self-construal scale used was developed by Gudykunst, Matsumoto, Ting-Toomey, Nishida, and Karimi (1994) and improved by Gudykunst and Lee (2003). This 
measure was drawn from instruments used in past research in many cultures (Hui, 1988; Markus \& Kitayama, 1991; Singelis, 1994; Verma, 1992; Yamaguchi, 1994). The Gudykunst et al. (1996) scale has 14 items and the scales have good reliability and validity as shown in previous studies (e.g., Hackman, Ellis, Johnson, and Staley (1999). All the items were measured using a 1 to 7 point scale $(1=$ strongly disagree to $7=$ strongly agree $)$.

The 14-item interdependent self-construal measure developed by Gudykunst and Lee (2003) was adopted. For the purpose of this study, three items related to work relationships were deleted, given that teenagers in urban areas of Brazil typically do not have jobs, and only a small proportion of our sample had one. Finally, a total of 11 items using a 1 to 7 point scale ( $1=$ strongly disagree to $7=$ strongly agree $)$ were used. They include: "It is important to consult close friends and get their ideas before making a decision”.

Materialism had 15 items assessing teenagers' materialism value using a 1 to 7 point scale. The measure was developed by Wong, Rindfleisch, and Burroughs (2003), and was tested in a cross-cultural setting. This scale is an adapted version (altered to use an interrogative question format) of the version of the material values scale (Richins, 2004; Richins \& Dawson, 1992). A sample question was: "How do you feel about people who own expensive homes, car, and clothes?" Past studies have reported that the scale demonstrates good reliability (e.g., Prendergast and Wong (2003) Rose and DeJesus (2007).

\section{Analysis Procedure}


First, we ran an exploratory factor analysis (EFA) using SPSS software version 23. We subjected all items to the EFA using varimax rotation. Using a cut-off eigenvalue of 1 (Kaiser, 1960) we found that there were five factors with accumulated variance explained of $52 \%$. We delete items that cross loaded onto more than one factor. With the inspection of the items forming the factors, we found that there are eight items measuring the materialism construct while there are eight items measuring the independent self-construal. For the items measuring the interdependent self-construal, there were three factors. Each factor had three items. The first subconstruct born from interdependent self-construal was renamed group dependency, and refers to a need to achieve the group's authorisation before any action; it includes three items (e.g., 'I consult others before making important decisions'). The second construct was named group loyalty and includes three items on putting the group interests ahead of one's own interests (e.g., 'I will sacrifice my self-interest for the benefit of my group'). Finally, group respect considers three items related to respecting group decisions (e.g., 'I respect decisions made by my group'). This all suggested a re-evaluation of our original hypotheses. While the first hypothesis (H1) continues to be reasonable, the second hypothesis had lost its meaning. We replaced $\mathrm{H} 2$ with three new hypotheses, $\mathrm{H} 2 \mathrm{a}, \mathrm{H} 2 \mathrm{~b}$ and $\mathrm{H} 2 \mathrm{c}$. Figure 2 diagrams the five construct model conceptually.

H1: Independent self-construal relates negatively to materialism.

H2a: Group dependency relates positively to materialism 
H2b: Group loyalty relates positively to materialism

H2c: Group respect relates positively to materialism

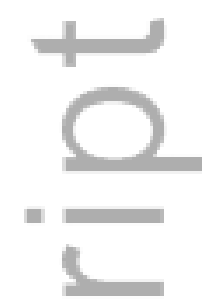

[Figure 2 Here]

Then we subjected the remaining 25 items measuring the specified five constructs to a confirmatory factor analysis using LISREL 9.1 (Jöreskog \& Sörbom, 2013). The initial fit indices indicated a good model fit $\left[\chi^{2}{ }_{314}=537.35, \chi^{2} / \mathrm{df}=1.71, p>0.001, \mathrm{RMSEA}=0.04, \mathrm{CFI}=\right.$ $0.96, \mathrm{NFI}=0.91, \mathrm{NNFI}=0.98]$. However, there were items that had low standardised factor loadings. Considering both statistical guidelines and evaluating the impact of deleting items on how a construct was defined, we sequentially deleted items with standardised factor loadings less than 0.50 . The final measurement model fits the data well $\left[\chi^{2}{ }_{109}=176.43, \chi^{2} / \mathrm{df}=1.61, p=0.02\right.$, $\mathrm{RMSEA}=0.03, \mathrm{CFI}=0.99, \mathrm{NFI}=0.95, \mathrm{NNFI}=0.98]$. The values for CFI, NFI and NNFI were greater than the recommended value of 0.90 while the RMSEA is less than 0.08 (Hu and Bentler, 1998).

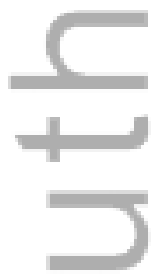

[Table 1 Here]

Convergent validity was supported, as the factor loadings were all significant (the lowest t-value was 9.11). The measurement model also demonstrated a reasonable level of reliability as 
the lowest construct reliability $(\mathrm{CN})$ was 0.72 , and the lowest Cronbach's alpha was 0.70 (Nunnally and Bernstein (1994). However, the average variance extracted (AVE) values were rather low. The lowest AVE was 0.40. However, as indicated by Fornell and Larcker (1981), the AVE is a more conservative measure of construct reliability. There are past studies that have also reported low value of AVEs (e.g., De Luca and Atuahene-Gima, 2007, Hanvanich et al., 2006). $=$ To satisfy the requirement of discriminant validity, the AVE for two constructs should exceed the squared correlation between them (Fornell and Larcker, 1981). It can be seen from Table 2, which presents the correlations among constructs, there is no evidence that a squared correlation between any two constructs was higher than either of the constructs' AVE. This provides support for discriminant validity among the constructs. In conclusion, the measurement model demonstrated satisfactory measurement properties.

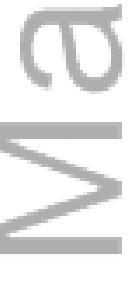

[Table 2 Here]

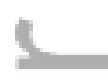

\section{RESULTS AND DISCUSSION}

Once the measurement model demonstrated reasonably good measurement properties, we proceeded to run the structural model. The structural model fits the data well $\left[\chi_{115}^{2}=335.40, \chi^{2} / \mathrm{df}\right.$ $=2.91, p<0.001, \mathrm{RMSEA}=0.06, \mathrm{CFI}=0.94, \mathrm{NFI}=0.91, \mathrm{NNFI}=0.93]$. As the structural model fits the data well, we proceed with the analyses of the hypotheses. The complete model's standardised solution is shown in Figure 3 and Table 3. 
[Figure 3 Here]

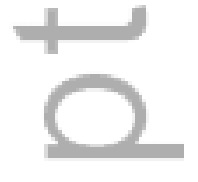

[Table 3 Here]

$\mathrm{H} 1$ is not supported since independent self-construal is positively related to materialism ( $\beta$ $=0.15 . \mathrm{t}$-value $=3.36$ ). While we hypothesise that the independent self-construal would be negatively related to materialism, the significant result for $\mathrm{H} 1$ is found, but in the opposite direction. It is unexpected to see that independent self-construal is positively affecting materialism. This result challenges our pre-conceived belief but is not necessarily unreasonable. Independent people, especially teenagers, may be drawn into materialistic behaviour in order to signal their difference with the rest. Additional explanation for the positive relationship between independent self-construal and materialism could rest on the fact that this research was done with Brazilian teenagers, a group seldom scrutinised in this class of research.

We expected interdependent self-construal to be positively related to materialism, since we hypothesised that more interdependent individuals would need to consume more of what others are consuming, in order to fit into the group. Teenagers are more invested with their friends, and would require somehow signalling their concordant personality to them. Nonetheless, the original construct was not homogeneous enough so it was divided into three sub-constructs. These revealed relationships between them, depicted in Table 3, which allows for much more thought-provoking analyses. H2a is supported as group dependency affects 
materialism positively $(\beta=0.20$. $\mathrm{t}$-value $=3.25)$. As expected, Brazilian teenagers who possesses high levels of group dependency tend to report high levels of materialism. This is because they want to achieve the group's authorisation to be part of the group and thus may increase their levels of materialism consumption to fit in the group they belong or aspire to belong to.

$\mathrm{H} 2 \mathrm{~b}$ is not supported, as group loyalty has no effect on materialism $(\beta=-0.01$. $\mathrm{t}$-value $=-$ 31). H2c is also not supported as group respect diminishes materialism $(\beta=-0.17$. $\mathrm{t}$-value $=-$ 3.81). While we hypothesise that group respect would be positively related to materialism, a significant result for $\mathrm{H} 2 \mathrm{c}$ is found, but in the opposite direction. Individuals with high respect for the decisions of the group seem to be the less affected by materialism, and this is actually the only construct to diminish it, which is something that we expected independent self to do.

\section{CONCLUSION}

Since there is no prior study that focuses on the relationship between self and materialism among teenagers, especially Brazilian teenagers, the results of this study suggest that both independent self and group dependency promotes materialism among Brazilian teenagers. Also, materialistic individuals represent a large consumer segment (Wiedmann, Hennigs, \& Siebels, 2009). The study of the Brazilian teen market reveals that retailers could shift marketing efforts to focus more on materialistic aspects of merchandising and advertising. Retail companies should understand that some teens relate with their own belief that money can buy them happiness and 
that acquiring material possessions is a form of demonstrating one's achievements in life (Banerjee \& Dittmar, 2008).

This research offers three main contributions. First, this study is an attempt to increase understanding of teenagers' self and materialism and the relationship between them. The focus was on how interdependent and independent self-construal affects teenagers' materialism levels. This research allows us to expand our understanding of the self and its different dimensions. Until now research has focused mainly on two types of self, independent and interdependent. It may be time to investigate a little deeper, and discover new levels of the self. One of the key findings of our study demonstrates that the self is a powerful force in developing materialism. Also, there are more dimensions of the self that should be studied. Our beliefs were partly justified; the self does translate into different levels of materialism among individuals. Yet, not all dimensions of the self-concept affect materialism equally. While both independent self and group dependency have positive impact on materialism, the group respect has a negative impact on materialism among teenagers. Since our some of our hypotheses are supported in the opposite direction, it should be a compelling task to strengthen these findings with more investigation.

Second, we test the conceptual model using data from a sample of teenagers. Since our conceptual model was tested using the data gathered from adolescents, we found interesting new focuses for research. Regardless, our conclusions need not be confined only to adolescents, since aspects like loyalty and respect (the sub-constructs of interdependent self) are also part of the daily life of adults. These results should be taken with prudence, but also interest, by researchers. 
Finally, this research focuses on Brazil. Another goal of the study was to examine the applicability of scales already tested in different cultures with Brazilian teenagers. The results are mixed, while independent self-construal responded well, interdependent self-construal did not. This may be because Brazilians do not share the traditional dimensions that have been internationally tested, or it could be that teenagers represent a more complex cohort to be $=$ analysed using the measurement scales developed for an adult cohort. It would be interesting to retest these dimensions in cultures in which they have already been tested, but with teenagers, in order to evaluate the real difference. This would be a good way to recognise if these results are born from the fact we studied adolescents, or because Brazilians do not share the same aspects other cultures do.

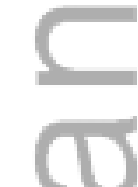

\section{LIMITATIONS AND FUTURE RESEARCH}

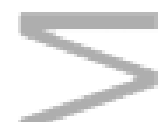

We should consider some possible shortcomings of our work, largely to do with the fact we used an adolescent's data base and discovered new features of their self. Considering this, perhaps some of the measures used lack sensitivity for our audience, which could make sense given that most of the work done until now has not been tested on teenagers, but on adults. More research is needed in order to be certain this is not the case, and eventually find new scales more appropriated for use with teenagers. In order to make the psychometric properties of the measures used in this study stronger, future studies can incorporate some qualitative investigation into 
wordings and meaning used for measurement scales to ensure their appropriateness for adolescents. This can be done prior to pretesting the quantitative questionnaire.

Second, since our hypotheses are supported in the opposite direction, future studies can consider replicating and extending our conceptual frame work. Future research should involve different countries and different measures in order to investigate if the relationships found in this study are applicable in different settings. Further investigation should shade more light into the conflicting findings and explain our results better. Also, some qualitative study can be conducted to further explain the findings of our research.

Finally, the nature of our research is cross-sectional. Further studies can be developed to investigate whether the relationship between self and materialism vary as the teenagers become older. In other word, future research can test the moderating role of age on the associations between various self and materialism.

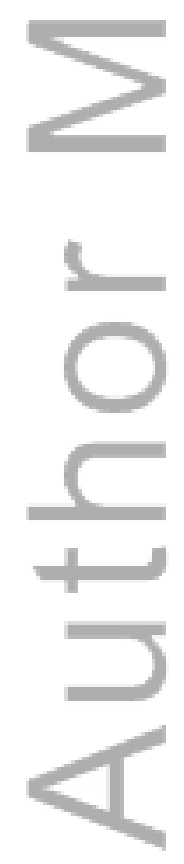




\section{References}

Abe, S., \& Bagozzi, R. P. (1996). An investigation of construct validity and generalizability of the self-concept: self-consciousness in Japan and the United States. In L. Manrai \& A. Manrai (Eds.), Global Perspectives in Cross-Cultural and Cross-National Consumer Research (pp. 242). New York, NY: Haworth Press.

Achenreiner, G. B. (1997). Materialistic values and susceptibility to influence in children.

= Advances in Consumer Research, 24(1), 82-88.

Agrawal, N., \& Maheswaran, D. (2005). The effects of self-construal and commitment on persuasion. Journal of Consumer Research, 31(4), 841-849.

Banaji, M. R., \& Prentice, D. A. (1994). The self in social contexts. Annual Review of Psychology, 45, 297-332.

Banerjee, R., \& Dittmar, H. (2008). Individual differences in children's materialism: The role of peer relations. Personality and Psychology Bulletin, 34(1), 17-31.

Belk, R. W. (1984). Three scales to measure constructs related to materialism: reliability, validity, and relationships to measures of happiness. Advances in Consumer Research, 11, 291-297.

Belk, R.W. (1985). Materialism: trait aspects of living in the material world. Journal of Consumer Research, 12(3), 265-280.

Belk, R. W. (1988). Possessions and self: John Wiley \& Sons, Ltd.

Brewer, M. B., \& Hewstone, M. (2004). Self and social identity. Malden, MA: Blackwell Publishing.

Bristol, T., \& Mangleburg, T. F. (2005). Not telling the whole story: teen deception in purchasing. Journal of the Academy of Marketing Science, 33(1), 79-95.

Campbell, J., Trapnell, P., Heine, S., Katz, I., Lavallee, L., \& Lehman, D. (1996). Self-concept clarity: measurement, personality correlates, and cultural boundaries. Journal of personality and social psychology, 70(1), 141-156. 
Clark, R. A. (2006). Consumer independence: conceptualization, measurement and validation of a previously unmeasured social response tendency. Florida State University, Tallahassee, FL.

Czikszentmihalyi, M., \& Rochberg-Halton, E. (1981). The meaning of things: somestic symbols of the self. Cambridge: Cambridge University Press.

Chaplin, L. N., \& John, D. R. (2007). Growing up in a material world: age differences in materialism in children and adolescents. Journal of Consumer Research, 34(4), 480-493.

Chee, B. (2013). Today's teens: More materialistic, less willing to work. http://newscenter.sdsu.edu/sdsu_newscenter/news_story.aspx?sid=74179

Churchill, G. A., \& Moschis, G. P. (1979). Television and interpersonal influences on adolescent consumer learning. Journal of Consumer Research, 6(1), 23-35.

Fields, S. (1999, January, 4). Growing up on fast forward, The Washington Times.

Gilles, K. (2014). The importance of adolescence. Population Reference Bureau.

Goldberg, M. E., Gorn, G. J., Peracchio, L. A., \& Bamossy, G. (2003). Understanding materialism among youth. Journal of consumer psychology, 13, 278-288.

Grubb, E. L., \& Grathwohl, H. L. (1967). Consumer self-concept, symbolism and market behavior: a theoretical approach. Journal of Marketing, 31(4), 22-27.

Grzeskowiak, S., \& Sirgy, M. J. (2007). Consumer well-being (CWB): the effects of self-image congruence, brand-community belongingness, brand loyalty, and consumption recency. Applied Research in Quality of Life, 2(4), 289-304.

Gudykunst, W. B., \& Lee, C. M. (2003). Assessing the validity of self construal scales. Human Communication Research, 29(2), 253-274.

Gudykunst, W. B., Matsumoto, Y., Ting-Toomey, S., Nishida, T., \& Karimi, H. (1994). Measuring self construals across cultures: a derived etic analysis. International Communication Association Convention in Sydney, Australia, July.

This article is protected by copyright. All rights reserved. 
Gudykunst, W. B., Matsumoto, Y., Ting-Toomey, S., Nishida, T., Kim, K., \& Heyman, S. (1996). The influence of cultural individualism-collectivism, self construals, and individual values on communication styles across cultures. Human Communication Research, 22(4), 510-543.

Gulland, C. (2006, July, 14). The ten biggest themes of 'What teens want'. Retrieved March, 20, 2007, from http://www.ypulse.com/the-ten-biggest-themes-of-what-teens-want

Hackman, M. Z., Ellis, K., Johnson, C. E., \& Staley, C. (1999). Self-construal orientation:

- validation of an instrument and a study of the relationship to leadership communication style. Communication Quarterly, 47(2), 183-195.

Higgins, E. T., Bond, R. N., Klein, R., \& Strauman, T. (1986). Self-discrepancies and emotional vulnerability: how magnitude, accessibility, and type of discrepancy influence affect. Journal of personality and social psychology, 51(1), 5-15.

Holman, T. B. (1981). The influence of community involvement on marital quality. Journal of Marriage and Family, 43(February), 143-149.

Hui, C. H. (1988). Measurement of individualism-collectivism. Journal of Research in Personality, 22(1), 17-36.

James, W. (1890). The principles of psychology (Vol. 1). New York, NY: Henry Holt.

John, D. R. (1999). Consumer socialization of children: a retrospective look at twenty-five years of research. Journal of Consumer Research, 26(December), 183-213.

Jöreskog, K. G., \& Sörbom, D. (2013). LISREL for windows.

Kantrowitz, B., \& Wingert, P. (1999, October 18). The truth about tweens. Newsweek, 62-79.

Kasser, T. (2002). The high price of materialism. Cambridge, MA: MIT Press.

Kleine, S. S., Kleine, R. E., \& Allen, C. T. (1995). How is a possession 'me' or 'not me?' characterizing types and an antecedent of material possession attachment. Journal of Consumer Research, 22(December), 327-343.

Kline, P. (2000). The handbook of psychological testing (2nd ed.). New York, NY: Routledge. 
Krech, D., Crutchfield, R. S., \& Ballachey, E. L. (1962). Individual in society: a textbook of social psychology. New York, NY: McGraw-Hill.

Lapowsky, I. (2014, March 3). Why teens are the most elusive and valuable customers in tech. Inc.

Larsen, V., Sirgy, M. J., \& Wright, N. D. (1999). Materialism: the construct, measures, antecedents, and consequences. Academy of Marketing Studies Journal, 3(2), 75-107.

$=$

Lindstrom, M. (2003). GRANDchild. London: Kogan Page.

Markus, H. R., \& Kitayama, S. (1991). Culture and the self: implications for cognition, emotion, and motivation. Psychological Review, 98(2), 224-253.

Markus, H. R., \& Kitayama, S. (1998). The cultural psychology of personality. Journal of Cross Cultural Psychology, 29, 63-87.

Markus, H. R., \& Wurf, E. (1987). The dynamic self-concept: a social psychological perspective. Annual Review of Psychology, 38(1), 299-337.

Mathur, A. (2013). Materialism and charitable giving: Can they co-exist? Journal of Consumer Behaviour, 12(3), 149-158.

Morningstar. (2014, September 4th). Consumer Observer August. 2014

Moses, E. (2000). The \$ 100 billion allowance-accessing the global teen market. New York: John Wiley \& Sons Inc.

Mukerji, C. (1983). From graven images: patterns of modern materialism. New York: Columbia University Press.

Muniz, A. M., \& O'Guinn, T. C. (2001). Brand community. Journal of Consumer Research, 27(March), 412-432.

Neisser, U. (1993). The perceived self: ecological and interpersonal sources of self-knowledge. Cambridge, UK: Cambridge University Press.

This article is protected by copyright. All rights reserved. 
Nunnally, J. C., \& Bernstein, I. H. (1994). Psychometric theory (3rd ed.). New York, NY: McGraw-Hill.

Pieters, R. (2013). Bidirectional dynamics of materialism and loneliness: not just a vicious cycle. Journal of Consumer Research, 40(4), 615-631.

Prendergast, G., \& Wong, C. (2003). Parental influence on the purchase of luxury brands of infant apparel: an exploratory study in Hong Kong. Journal of Consumer Marketing, $20(2 / 3), 157-169$.

Richins, M. L. (1987). Media, materialism, and human happiness. Advances in Consumer Research, 14, 352-356.

Richins, M. L. (1994a). Special possessions and the expression of material values. Journal of Consumer Research, 21(3), 522-533.

Richins, M.L. (1994b). Valuing things: the public and private meanings of possessions. Journal of Consumer Research, 21(3), 504-521.

Richins, M. L. (2004). The material values scale: Measurement properties and development of a short form. Journal of Consumer Research, 31(1), 209-219.

Richins, M. L., \& Dawson, S. (1992). A consumer values orientation for materialism and its measurement: scale development and validation. Journal of Consumer Research, 19(3), 303-316.

Rindfleisch, A., Burroughs, J. E., \& Denton, F. (1997). Family structure, materialism, and compulsive consumption. Journal of Consumer Research, 23(4), 312-325.

Roberts, J. A., Tanner, J. F., \& Manolis, C. (2005). Materialism and the family structure-stress relation. Journal of consumer psychology, 15(2), 183-190.

Rose, P., \& DeJesus, S. P. (2007). A model of motivated cognition to account for the link between self-monitoring and materialism. Psychology \& Marketing, 24(2), 93.

Schaefer, A. D., Hermans, C. M., \& Parker, R. S. (2004). A cross-cultural exploration of materialism in adolescents. International Journal of Consumer Studies, 28(4), 399-411.

This article is protected by copyright. All rights reserved. 
Shavelson, R. J., Hubner, J. J., \& Stanton, G. C. (1976). Self-concept: validation of construct interpretations. Review of educational research, 46(3), 407-441.

Siegel, D. L., Coffey, T. J., \& Livingston, G. (2001). The great tween buying machine. Ithaca, NY: Paramount Market.

Singelis, T. M. (1994). The measurement of independent and interdependent self-construals. Personality and social psychology bulletin, 20(5), 580- 591.

Sirgy, M. J. (1982). Self-concept in consumer behavior: a critical review. Journal of Consumer Research, 9(Dec), 287-537.

Sirgy, M. J., Lee, D.-J., Johar, J. S., \& Tidwell, J. (2008). Effect of self-congruity with sponsorship on brand loyalty. Journal of Business Research, 61(10), 1091-1097.

Solomon, M. R. (1983). The role of products as social stimuli: a symbolic interactionism perspective. Journal of Consumer Research, 10(3), 319-329.

Song, D., \& Lee, J. (2013). Balancing "We" and "I": Self-construal and an alternative approach to seeking uniqueness. Journal of Consumer Behaviour, 12(6), 506-516.

Todd, S. (2001). Self-concept: a tourism application. Journal of Consumer Behaviour, 1(2), 184196.

Tsai, S.-p. (2006). Investigating how the message framing strategy impacts brand marketing. Web Journal of Chinese Management Review, 9(2), 1-29.

Verma, J. (1992). Allocentrism and relational orientation. In Y. S. Iwaki, Kashima, \& K. Leung (Ed.), Innovation in Cross-Cultural Psychology (pp. 152-163). Lisse, Netherlands: Swets and Zeitlinger.

Vigneron, F. (1998). Multiple-item scale for measuring prestige perceptions of brands. The University of Sydney, Sydney, Australia.

Vigneron, F., \& Johnson, L. W. (2004). Measuring perceptions of brand luxury. Journal of Brand Management, 11(6), 484-506.

This article is protected by copyright. All rights reserved. 
Wallendorf, M., \& Arnould, E. (1988). My favorite things: a cross-cultural inquiry into object attachment, possessiveness, and social linkage. Journal of Consumer Research, 14(March), 531-547.

Ward, S., \& Wackman, D. (1971). Family and media influences on adolescent consumer learning. American Behavioral Scientist, 14(3), 415-428.

Wiedmann, K.-P., Hennigs, N., \& Siebels, A. (2009). Value-based segmentation of luxury consumption behavior. Psychology and Marketing, 26(7), 625-651.

Wong, N. Y., \& Ahuvia, A. C. (1998). Personal taste and family face: luxury consumption in confucian and western societies. Psychology \& Marketing, 15(5), 423-441.

Wong, N. Y., Rindfleisch, A., \& Burroughs, J. E. (2003). Do reverse-worded items confound measures in cross-cultural consumer research? The case of the material values scale. Journal of Consumer Research, 30(1), 72-91.

Yamaguchi, S. (1994). Collectivism among the Japanese: a perspective from the self. In H. T. U. Kim, Ç. Kagitçibasi, S. Choi, \& G. Yoon (Ed.), Individualism and Collectivism: Theory, Method, and Applications (Vol. 18, pp. 175-188). Thousand Oaks, CA: Sage.

Youniss, J., \& Smollar, J. (1985). The individual and relations. In J. Youniss \& J. Smollar (Eds.), Adolescent Relations with Mothers, Fathers and Friends (pp. 160-176). Chicago: University of Chicago Press.

Zinkhan, G. M. (1994). Advertising, materialism, and quality of life. Journal of Advertising, 23(2), 1-4.

Zollo, P. (1999). Not quite the TV generation. American Demographics, 21(5), 35-37.

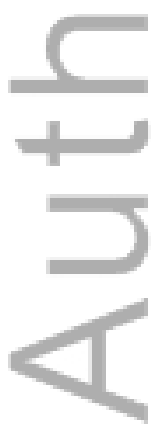


Figure 1: Conceptual Simple Model

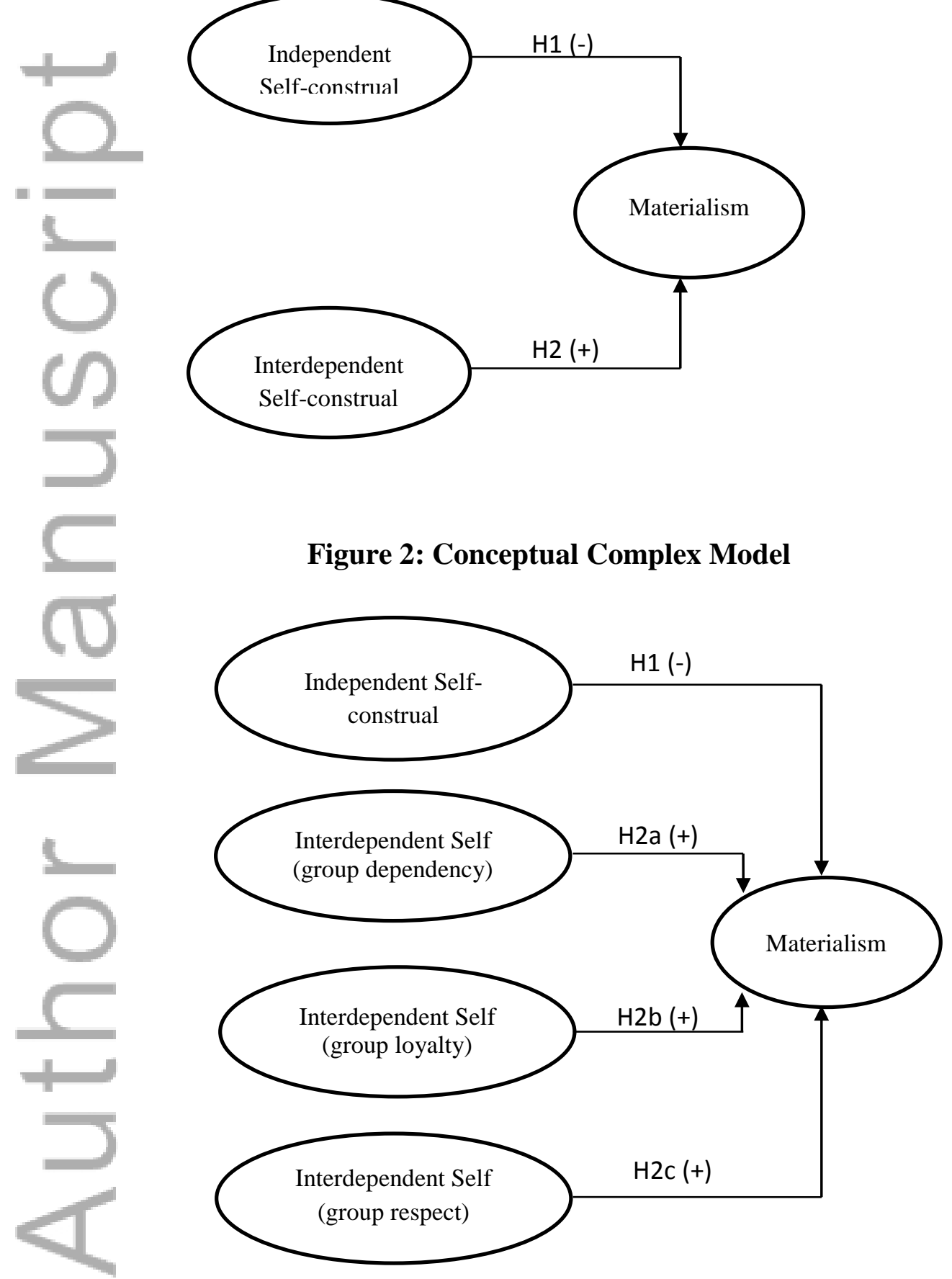


Figure 3: Complex Model (standardised solution)

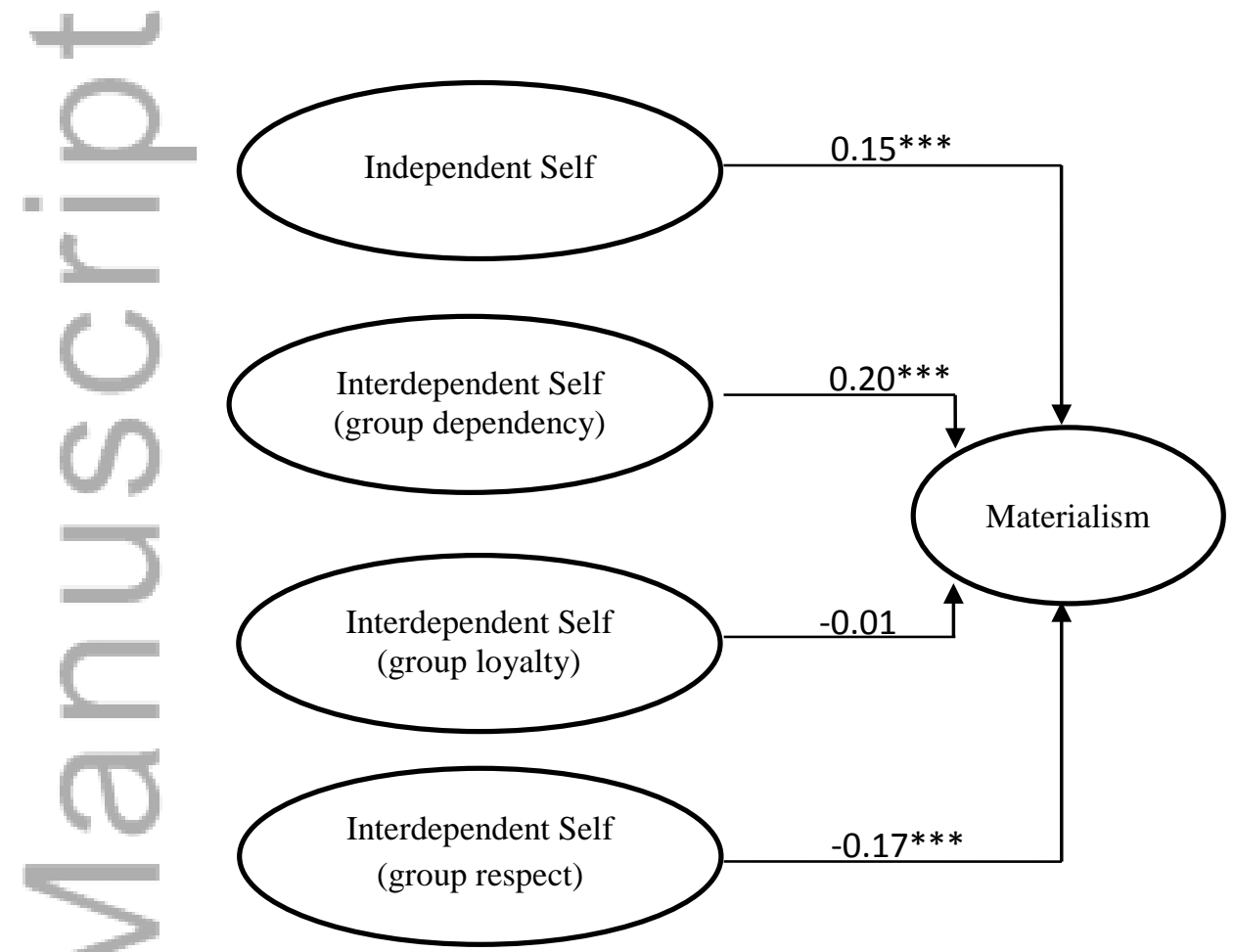

* Significant at $\leq 0.05$ level (two tail test).

$* *$ Significant at $\leq 0.01$ level (two-tailed test).

$* * *$ Significant at $\leq 0.001$ level (two-tailed test).

$>$

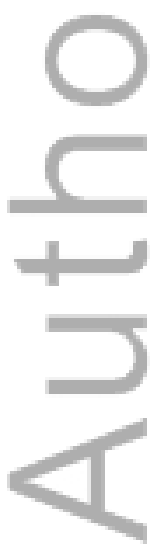

This article is protected by copyright. All rights reserved. 
Table 1: Measures

\begin{tabular}{|c|c|}
\hline Measures & $\begin{array}{l}\text { Std. factor } \\
\text { loadings }\end{array}$ \\
\hline Materialism $(\alpha=0.70, \mathrm{CN}=0.72$, and $\mathrm{AVE}=.40)$ & \\
\hline $\begin{array}{l}\text { How do you feel about people who own expensive homes, cars, and cloths? } \\
\text { ( } 1=\text { do not admire to } 7=\text { greatly admire })\end{array}$ & 0.50 \\
\hline $\begin{array}{l}\text { How do you approach your life in terms of your possessions (i.e., buying and } \\
\text { owning things)? ( } 1=\text { simple is better to } 7=\text { more is better) }\end{array}$ & 0.65 \\
\hline $\begin{array}{l}\text { Would your life be any better if you owned certain things that you don't have? } \\
(1=\text { not any better to } 7=\text { much better) }\end{array}$ & 0.79 \\
\hline $\begin{array}{l}\text { What do the things you own say about how well you are doing in life? }(1=\text { very } \\
\text { little to } 7=\text { a great deal })\end{array}$ & 0.52 \\
\hline Independent Self-construal $(\alpha=0.74, \mathrm{CN}=0.77$, and $\mathrm{AVE}=.46)$ & \\
\hline I prefer to be self-reliant rather than depend on others. & 0.72 \\
\hline I try not to depend on others. & 0.75 \\
\hline It is important for me to act as an independent person. & 0.73 \\
\hline I should decide my future on my own. & 0.50 \\
\hline Group dependency $(\alpha=0.70, \mathrm{CN}=0.74$, and $\mathrm{AVE}=.50)$ & \\
\hline I consult others before making important decision. & 0.55 \\
\hline It is better to consult others and get their opinion before doing anything. & 0.74 \\
\hline $\begin{array}{l}\text { It is important to consult close friends and get their ideas before making a decision. } \\
\text { Group loyalty }(\alpha=0.72, \mathrm{CN}=0.73 \text {, and } \mathrm{AVE}=.50)\end{array}$ & 0.72 \\
\hline I will sacrifice my self-interest for the benefit of my group. & 0.52 \\
\hline I will stay in a group if it needs me, even if I am not happy with it. & 0.82 \\
\hline $\begin{array}{l}\text { I remain in the groups of which I am a member if they need me, even though I am } \\
\text { dissatisfied with them. }\end{array}$ & 0.71 \\
\hline Group respect $(\alpha=0.71, \mathrm{CN}=0.73$, and $\mathrm{AVE}=.50)$ & \\
\hline I respect decisions made by my group. & 0.80 \\
\hline I maintain harmony in the groups of which I am a member. & 0.52 \\
\hline I respect the majority's wishes in groups of which I am a member. & 0.72 \\
\hline
\end{tabular}

$\chi_{314}^{2}=537.35, \chi^{2} / \mathrm{df}=1.71, p>0.001, \mathrm{RMSEA}=0.04, \mathrm{CFI}=0.96, \mathrm{NFI}=0.91, \mathrm{NNFI}=0.98$ 
Table 2: Descriptive statistics: Means, standard deviation and correlations

\begin{tabular}{lccccccc}
\hline Constructs & Mean & $\begin{array}{c}\text { Std. } \\
\text { deviation }\end{array}$ & 1 & 2 & 3 & 4 & 5 \\
\hline 1. Materialism & 4.16 & 1.13 & & & & & \\
2. Independent self-construal & 5.46 & 1.16 & $0.15^{* *}$ & & & & \\
3. Group dependency & 4.93 & 1.40 & $0.12^{* *}$ & $0.11^{*}$ & & & \\
4. Group loyalty & 4.11 & 1.55 & -0.02 & $0.11^{*}$ & $0.26^{* *}$ & & \\
5. Group respect & 5.41 & 1.26 & $-0.08^{*}$ & $0.18^{* *}$ & $0.25^{* *}$ & $0.36^{* *}$ & \\
\hline
\end{tabular}

*Significant at $\leq 0.05$ level (two-tailed test).

**Significant at $\leq 0.01$ level (two-tailed test).

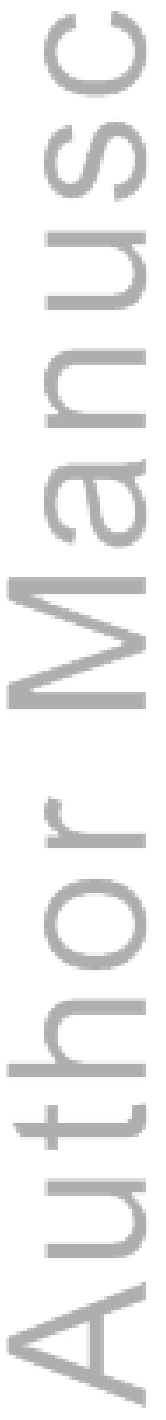


Table 3: Standardised Solution - Estimates and t-values

\begin{tabular}{cccc} 
Hypothesis & \multicolumn{2}{c}{ Standardised Solution } \\
\cline { 3 - 4 } & & Estimate & t-value \\
\hline Independent Self $\rightarrow$ Materialism & $\mathrm{H} 1$ & $0.15^{* * *}$ & 3.36 \\
Group Dependency $\rightarrow$ Materialism & $\mathrm{H} 2 \mathrm{a}$ & $0.20^{* * *}$ & 3.25 \\
Group Loyalty $\rightarrow$ Materialism & $\mathrm{H} 2 \mathrm{~b}$ & -0.01 & -0.31 \\
Group Respect $\rightarrow$ Materialism & $\mathrm{H} 2 \mathrm{c}$ & $-0.17^{* * *}$ & -3.81 \\
\hline
\end{tabular}

*Significant at $\leq 0.05$ level (two-tailed test).

**Significant at $\leq 0.01$ level (two-tailed test).

$* * *$ Significant at $\leq 0.001$ level (two-tailed test).

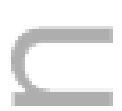

0

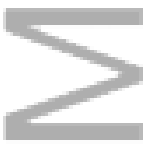

2

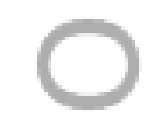

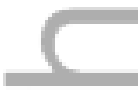

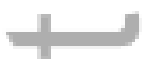

rans

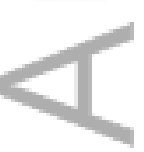

This article is protected by copyright. All rights reserved. 


\section{University Library}

\section{- M M I E R R V A gateway to Melbourne's research publications}

Minerva Access is the Institutional Repository of The University of Melbourne

Author/s:

de Araujo Gil, L;Leckie, C;Johnson, L

Title:

The impact of self on materialism among teenagers

Date:

2016-05-01

Citation:

de Araujo Gil, L., Leckie, C. \& Johnson, L. (2016). The impact of self on materialism among teenagers. JOURNAL OF CONSUMER BEHAVIOUR, 15 (3), pp.281-288. https:// doi.org/10.1002/cb.1573.

Persistent Link:

http://hdl.handle.net/11343/290955 